Fikroh : Jurnal Pemikiran dan Pendidikan Islam

Volume. 13, Number. 1, Januari 2020

p-ISSN : 2087-7501, e-ISSN : 2715-4459

HIm : 33-43

Journal Home Page : https://jurnal.stai-alazharmenganti.ac.id/index.php/fikroh

\title{
PENGARUH PENDIDIKAN FORMAL ORANG TUA TERHADAP PERKEMBANGAN SOSIAL EMOSIONAL ANAK DI MADRASAH IBTIDAIYAH THORIQUS SALAM SIDOARJO
}

\author{
Abd. Hakim \\ IAI Al Khoziny Budura, Sidoarjo \\ Abd.hakim@gmail.com
}

\begin{abstract}
Elementary School education is a coaching effort undertaken for 6-year-old children carried out with the help of educational stimuli to support physical and spiritual growth and development so that children have readiness in education to continue. Efforts given to early childhood are in the form of stimulating, guiding and nurturing and providing learning activities that will produce children's abilities and skills that are adapted to the child's development in the past. This is based on Law No. 20 of 2003 concerning the national education system Chapter 1, Article 1, Item 14. In accordance with the research questions that have been raised, the purpose of the study is to find out the parents' formal education towards the social development of children in Madrasah Ibtidaiyah Thoriqussalam Sidoarjo. There is a significant influence between formal education on children's emotional social development in $\mathrm{R} A$ Madrasah Ibtidaiyah Thoriqussalam Sidoarjo. Two independent variables namely formal education are correlated, with different significance. The bigher the formal education the better the higher the social development of children or vice versa which is being discussed with the regression analysis that occurs. Based on the research conclusions, the authors can propose the following suggestions: (1) Early Childhood Education teachers can consider that there are dominant factors regarding formal education that can facilitate children's emotional social development in addition to other factors (2) Adjusting patterns the mindset or perspective between teachers and students, intensive communication is improved between teachers and funds. In bringing this mindset together, teachers and parents must sit together, discuss what education can be done at home and what education should be done at school.
\end{abstract}

Keywords: social emotional, emotional

Abstrak 
Pendidikan dasar adalah suatu upaya pembinaan yang ditunjukkan kepada anak sejak lahir sampai dengan usia 6 tahun yang dilakukan dengan pemberian rangsangan pendidikan untuk membantu pertumbuhan dan perkembangan jasmani dan rohani agar anak memilki kesiapan dalam memasuki pendidik an lebih lanjut. Upaya yang diberikan pada anak usia Sekolah Dasar adalah dalam bentuk menstimulus, membimbing dan mengasuh serta pemberian kegiatan pembelajaran yang akan menghasilkan kemampuan dan keterampilan anak yang disesuaikan dengan tahap-tahap perkembangan yang di lalui anak usia Sekolah Dasar. Hal tersebut berdasarkan UU No. 20 tahun 2003 tentang sistem pendidikan nasional Bab 1, Pasal 1, Butir 14. Sesuai dengan pertanyaan penelitian yang telah dikemukakan, maka tujuan penelitian adalah untuk mengetahui korelasi pendidikan formal Orangtua terhadap perkembangan sosial emosi anak di Madrasah Ibtidaiyah Thoriqussalam Sidoarjo. Terdapat pengaruh yang signifikan antara pendidikan formal terhadap perkembangan sosial emosional anak di Madrasah Ibtidaiyah Thoriqussalam Sidoarjo. Dua variable independent yaitu pendidikan formal orangtua berkorelasi, dengan signifikansi berbeda,. Semakin tinggi pendidikan formal semakin baik akan berpengaruh lebih tinggi juga terhadap perkembangan sosial emosional anak atau sebaliknya hal ini ditunjukkan dengan analisis regresi yang terjadi. Berdasarkan kesimpulan penelitian, maka penulis merekomendasikan berupa saran-saran sebagai berikut: (1) Para guru Pendidikan Madrasah/SD dapat memahami ada faktor yang dominan yaitu pendidikan formal orangtua juga dapat mempengaruhi perkembangan sosial emosional anak di samping faktor-faktor lainnya (2) Menyamakan pola pikir atau pola pandang antara guru dengan orangtua siswa, disertai komunikasi intensif antara guru dan orangtua. Dalam mempertemukan pola pikir ini guru dan orang tua harus duduk bersama, membicarakan pendidikan apa saja yang bisa dilakukan dirumah dan pendidikan apa saja yang harus dilakukan di sekolah.

Kata kunci: social emosional, orangtua

\section{A. Pendahuluan}

Anak sejak lahir yang dilakukan dengan pemberian rangsangan pendidikan untuk membantu pertumbuhan dan perkembangan jasmani dan rohani agar anak memilki kesiapan dalam memasuki pendidikan lebih lanjut. Upaya yang diberikan pada anak usia Sekolah Dasar adalah dalam bentuk menstimulus, membimbing dan mengasuh serta pemberian kegiatan pembelajaran yang akan menghasilkan kemampuan dan keterampilan anak yang disesuaikan dengan tahap-tahap perkembangan yang di lalui anak usia Sekolah Dasar. Hal tersebut berdasarkan UU No. 20 tahun 2003 tentang sistem pendidikan 
nasional Bab 1, Pasal 1, Butir14. ${ }^{1}$

Anak usia Sekolah Dasar merupakan sosok individu yang sedang dalam proses perkembangan. Perkembangan anak adalah segala perubahan yang terjadi pada anak yang meliputi seluruh aspek, baik perkembangan fisik motorik, perkembangan kognitif, perkembangan bahasa, perkembangan sosial emosional anak serta perkembangan moral agama anak. ${ }^{2}$ Salah satu aspek perkembangan anak usia Sekolah Dasar yang perlu di perhatikan adalah aspek sosial emosional. Perkembangan sosial emosional merupakan dua aspek yang berlainan, namun dalam kenyataannya satu sama lain saling mempengaruhi. Perkembangan sosial sangat erat hubungannya dengan perkembangan emosional, walaupun masing-masing ada kekhususannya.

Perkembangan sosial emosional anak usia Sekolah Dasar perlu di stimulus karena pertama, makin kompleksnya permasalahan kehidupan di sekitar anak, termasuk di dalamnya perkembangan IPTEKS yang banyak memberikan tekanan pada anak, dan mempengaruhi perkembangan emosi maupun sosial anak. Kedua, adalah penanaman kesadaran bahwa anak adalah praktisi dan investasi masa depan yang perlu dipersiapkan secara maksimal, baik aspek perkembangan emosinya maupun keterampilan sosialnya, ketiga karena rentang usia penting pada anak terbatas. Jadi, harus difasilitasi seoptimal mungkin agar tidak ada satu fase pun yang terlewatkan, keempat ternyata anak tidak bisa hidup dan berkembang dengan IQ semata, tetapi EI jauh lebih dibutuhkan sebagai bekal kehidupan, kelima telah tumbuh kesadaran pada setiap orang tua tentang tuntutan untuk membekali kecerdasan sosial emosional sejak Sekolah Dasar pada anak. Terdapat kecenderungan yang sama di seluruh dunia, yaitu generasi sekarang lebih banyak memiliki kesulitan emosional dari pada generasi sebelumnya sehingga berdampak pada kemampuan sosialnya.

Dengan demikian perlu ada upaya peningkatan kecerdasan emosional yaitu usahausaha yang diarahkan pada pengembangan dan peningkatan kecerdasan emosional berupa usaha-usaha yang di arahkan pada pengembangan dan peningkatan kualitas emosional

\footnotetext{
${ }^{1}$ UU, Undang-Undang Sistem Pendidikan Nasional: UU RI No. 20 Tabun 2003 dan Peraturan Pelaksanaan (Jakarta: Departemen Pendidikan Nasional, 2003).

${ }_{2}^{2}$ Ahmad Susanto, Perkembangan Anak Usia Dini (Jakarta: Kencana Prenadamedia Grup), 14.
} 
anak sehingga mampu mengenali perasaan diri sendiri, perasaan orang lain, mampu memotivasi diri sendiri serta mampu mengelola emosi dan prilaku sosial menjadi lebih baik. Kita sebagai pendidikan harus mengoptimalkan pengembangan dan peningkatan kemampuan sosial emosional anak sehingga anak akan berkembangan secara optimal. Melihat kenyataan bahwa demikian kompleksnya permasalahan tentang perkembangan sosial emosional anak usia Sekolah Dasar, sudah seharusnya sekolah memaksimalkan perannya untuk turut mengembangkan berbagai kebutuhan anak didalam proses perkembangan sosial emosional anak usia Sekolah Dasar. Berbagai kendala dan hambatan sebagai mana yang dimaksud adalah seperti yang peneliti temukan di Madrasah Ibtidaiyah Thoriqussalam Sidoarjo adalah sebagian anak tidak mampu bekerja sama dengan temannya, ketika guru memberikan tugas untuk dilakukan bersama-sama maka anak akan lebih cenderung bekerja masing-masing tanpa menghiraukan perintah dari guru untuk bekerja secara berkelompok. Padahal bekerja sama pada anak usia, Sekolah Dasar penting karena dapat memupuk rasa persaudaraan, melatih diri untuk menghargai orang lain dan berlatih untuk mengungkapkan pendapat.

\section{B. Hasil dan Pembahasan}

Hubungan persahabatan diantara anak juga menyebabkan kecenderungan di antara anak-anak untuk membentuk kelompok-kelompok tertentu yang sesuai dengan kenyamanan anak, pembentukan kelompok ini tidak selamanya menimbulkan dampak positif bagi perkembangan seseorang, tetapi sebagian besar adanya kelompok-kelompok tertentu itu mengakibatkan dampak negative bagi seseorang. Contohnya kelompok tertentu mengucilkan bahkan sampai membuli anak yang mereka anggap berbeda. Masalah lainnya yang peneliti temukan adalah anak malu untuk mengungkapkan pendapat dan berbicara di depan umum serta anak bersikap kasar dan sulit meminta maaf terhadap temannya merupakan kebiasaan yang sering di lakukan anak di Madrasah Ibtidaiyah Thoriqussalam Sidoarjo tersebut.

Sedangkan menurut Hurlock, ada empat tahapan perkembangan kognitif antara lain: 1) sensorimotor (0-2 tahun), 2) praoperasional (2-7 tahun), 3) operasional konkrit (712 tahun), 4) operasional (12 tahun ke atas). Anak usia prasekolah atau usia MI termasuk pada tahap praoperasional dimana anak sudah mampu menggunkan simbol-simbol dalam 
pikirannya untuk mempresentasikan benda-benda atau kejadian serta menjelaskan suatu perbedaan. ${ }^{3}$ Perkembangan kognitif ini sering dikaitkan dengan kecerdasan anak dalam mengelompokkan benda, mengeksplorasi, dan membedakan benda atau suatu kejadian disekitar anak. Kemampuan ini termasuk kedalam perkembangan Sains.

Perkembangan Sains merupakan kemampuan berpikir anak yang meliputi kemampuan mengetahui, mengamati, memahami, melakukan percobaan dan memecahkan masalah yang ada di lingkungannya. ${ }^{4}$ Untuk mengembangkan Perkembangan Sains anak dapat berinteraksi dengan alam, mengetahui konsep-konsep pembelajaran di alam dan mengembangkan pengetahuan anak tentang makhluk hidup. Dalam pendidikan anak prasekolah pembelajaran sains sangat penting. Pembelajaran sains dapat menjadikan anak berada pada suatu pembentukan karakter dan sebagai individu yang harus berkembang di dunia danlingkungannya.

Sains menurut Yulianti adalah sebuah produk dan proses. Sebagai produk, sains merupakan batang tubuh pengetahuan yang terorganisis dengan baik mengenai dunia fisik dan alami. Sebagai proses, sains merupakan kegiatan menelusuri, mengamati dan melakukan percobaan. ${ }^{5}$ Menurut Wenham jurnalnya menyatakan: "Science is "a way of exploring and investigating the world around us... not only a way of knowing; it is... a way of doing". Science involves the discovery of factual knowledge (that something is true), causes for what is observed (why something occurs), and procedures (how something is investigated)."

Sains merupakan sebuah cara dalam mengeksplorasi dan menyelidiki dunia di sekitar kita. Sains untuk anak dapat melibatkan kegiatan penemuan, membuktikan kebenaran, mencari tahu sebab sesuatu terjadi dan prosedural (bagaimana sesuatu diselidiki). Sedangkan menurut Peraturan Pemerintah No. 58 Tahun 2009, tingkat pencapaian perkembangan Perkembangan Sains pada anak usia taman kanak-kanak yaitu, usia 4-<5 tahun: 1) mengenal benda berdasarkan fungsinya, 2) menggunakan benda-benda sebagai permainan simbolik, 3) mengenal gejala sebab akibat, 4) mengenal konsep sederhana dalam kehidupan, dan mengkreasikan sesuatu berdasarkan idenya. Pada anak

\footnotetext{
${ }^{3}$ Elizabeth Hurlock. Perkembangan Anak Jilid I Edisi Keenam. (Jakarta: Erlangga, 2010), 243.

${ }^{4}$ Yuliani Nurani, Sujiono, Konsep Dasar Pendidikan Anak Usia Dini (Jakarta: PT. Indeks, 2005), 12.

5 Yuliani Nurani, Konsep Dasar Pendidikan Anak Usia Dini.

6 Doris Bergen, "The Role of Pretend Playing Children's Cognitive Development" Early Childhood Research and Practice (Online) 2, No. 1 (Januari, 2002): 1-15.
} 
usia 5-6 tahun, tingkat pencapaian perkembangan Perkembangan Sains anak terdiri dari: 1) mengklasifikasikan benda berdasarkan fungsinya, 2) menunnjukkan aktivitas yang bersifat eksploratif dan menyelidiki, 3) menyusun perencanaan kegiatan yang akan dilaksanakan, 4) mengenal sebab-akibat tentang lingkungan, 5) menunjukkan inisiatif dalam memilih tema permainan, 6) memecahkan masalah sederhana. Semuanya dikembangkan dengan tujuan agar anak dapat mengetahui dan memahami konsep sains.

Sains bermanfaat bagi anak karena dapat menciptakan suasana yang menyenangkan serta dapat menimbulkan imajinasi-imajinasi pada anak yang pada akhirnya dapat menambah pengetahuan anak secara alamiah. Imajinasi-imajinas yang terbentuk akan memunculkan sebuah kreativitas. Melalui pengenalan dan pengembangan aspek sains pada anak usia Sekolah Dasar akan menumbuhkan rasa ingin tahu yang tinggi. Setting dan lingkungan belajar sains yang disediakan akan merangsang anak untuk memunculkan pertanyaan-pertanyaan menakjubkan dan tak terduga. Hal ini merupakan wujud dari berpikir dan belajar kreatif yang akan memunculkan kreativitas anak dalam sains. ${ }^{7}$

Kreativitas anak baik dalam sains maupun dalam bidang kemampuan lain sangat penting untuk dikembangkan karena anak usia 5-6 tahun memang sangat aktif dalam bergerak dan memerlukan berbagai stimulasi positif. Hal itu sesuai dengan teori Maria Montessori yang menekankan bahwa usia lahir sampai enam tahun merupakan masa peka, dimana dalam masa peka tersebut merupakan masa yang sangat baik dalam mengembangkan setiap potensi perkembangan yang dimiliki oleh anak, sehingga diperlukan kondisi dan stimulasi yang sesuai dengan kebutuhan pertumbuhan dan perkembangan anak tersebut.: "In the Montessori tradition these periods, signal the opening of windows of developmental opportunity. During these transient periods of heightened interest chil dren tend to focus their attention on particular object and activities, while ignoring other aspects of the environment. Each special interest is so intense that 'it leads its possessor to perform a certain series of actions ....with an outpouring of energy incredible to us".

Pernyataan tersebut dapat diartikan bahwa anak harus diberikan kesempatan dan kebebasan dalam bergerak serta mengamati benda-benda yang ada di sekitar melalui

\footnotetext{
${ }^{7}$ Supranata, Analisis Validitas, Reliabilitas dan Interpretasi Hasil Tes, Implementasi Kurikulum 2004.

8 John W. Creswell, Research Design Pendekatan Kualitatif, Kuantitatif dan Mixed (Yogyakarta: Pustaka Pelajar). 8
} 
kehidupannya sehari-hari. Satu hal yang cukup menonjol pada masa ini adalah munculnya berbagai bentuk kreativitas dalam bermain, sehingga periode ini seringkali dinamakan sebagai masa kreatif. Kreativitas yang ditunjukkan anak pada masa ini merupakan bentuk kreativitas yang original dengan frekuensi kemunculannya yang seolah tanpa terkendali dibandingkan dengan masa-masa lain dalam kehidupan seorang anak setelah masa ini berlalu. ${ }^{9}$ Menurut Sujiono, kreativitas pada setiap anak perlu dikenali, dipupuk, dan dikembangk an melalui stimulasi yang tepat agar kreativitas anak dapat terwujud. Potensi kreatif yang terdapat dalam diri setiap individu dapat diobservasi saat anak melakukan kegiatan bermain, karena bermain adalah dunia anak dan umumnya terjadi secara alamiah.Melalui kegiatan bermain, anak mampu mengembangkan potensi yang tersembunyi di dalam dirinya secara aman, nyaman, dan menyenangkan. ${ }^{10}$

Kemampuan untuk memunculkan kreativitas dalam kegiatan pembelajaran merupakan tantangan yang dihadapi pada zaman sekarang ini. Hal ini menjadi perlu adanya inovasi dalam kegiatan pembelajaran pada anak MI dengan tujuan untuk meningkatkan kreativitas anak dengan maksud untuk memberikan stimulus dalam perkembanganya. Pada kenyataannya, masih ada sebagian orang yang berpikir bahwa bermain hanya penting untuk mengisi waktu luang anak. Pandangan ini tentu saja tidak benar karena bagi anak, bermain merupakan pekerjaan dan alat yang digunakannya untuk bekerja adalah alat permainannya. Melalui bermain, anak belajar mengenali diri dan dunia sekitarnya melalui eksplorasi dan meneliti berbagai hal yang dilihat, didengar, dan dirasakannya. Namun pelaksanaan pembelajaran banyak yang belum mengkaidahkan bahwa pembelajaran di MI merupakan pembelajaran yang dilakukan melalui bermain.

Pelaksanaan pembelajaran saat ini lebih cenderung berfokus pada kegiatan akademik seperti membaca, menulis, dan menghitung. Kegiatan belajar lebih menekankan pada keterampilan akademik mengabaikan kegiatan bermain sebagaimana tuntutan perkembangan anak. Penyelenggaraan pembelajaran saat ini cenderung mengacu kepada kekeliruan konsepsi tentang pembelajaran anak usia Sekolah Dasar. ${ }^{11}$ Sebenarnya masa anak usia Sekolah Dasar ialah masa bermain. Hampir semua pendidik yang terlibat dalam

\footnotetext{
${ }_{9}$ Departemen Pendidikan Nasional, Beyond Centres and Circle Time Dalam Pendidikan Anak Usia Dini

${ }^{10}$ Sujiono, Yuliani Nurani, Konsep Dasar Pendidikan Anak Usia Dini.

11 Anita Yus, Model Pendidikan Anak Usia dini (Jakarta: Kencana Prenadamedia Grup, 2014), 45.
} 
kegiatan sekolah, mengetahui kalimat ini. Namun, pada praktiknya kalimat ini menjadi hilang sehingga belajar di SD/MI hampir tidak berbeda dengan belajar di jenjang pendidikan yang lain. Sifat akademistik sangat kental dalam pembelajaran sehari-hari. Situasi bermain hampir tidak kelihatan. Sistem pembelajaran yang demikian mengakibatkan anak tertekan dan mengalami kejenuhan dalam proses pembelajaran. ${ }^{12}$

Fenomena di atas nampak pula pada proses pembelajaran di MI Kabupaten Sidoarjo. Proses pembelajaran sebagaian besar dilakukan kurang memperhatihkan hakikat pembelajaran anak usia Sekolah Dasar. Pelaksanaan pembelajaran lebih cenderung berfokus pada kegiatan akademik seperti membaca, menulis, dan menghitung. Kegiatan belajar lebih menekankan pada keterampilan akademik dan mengabaikan kegiatan bermain. Hal ini terjadi pula pada pembelajaran sains untuk anak. Pembelajaran sains dilakukan hanya sebatas pengenalan sains dengan media. Pengembangan kemampuan proses sains pada anak-anak masih belum optimal dilakukan. Hal ini terjadi karena dalam pembelajaran sains dan pengembangan kreativitas dilakukan hanya sebatas pembelajaran dengan buku-buku penunjang, media dan kegiatan yang cenderung monoton. Sehingga menjadikan anak-anak kurang leluasa untuk mencoba dan mengeksplori hal-hal baru karena pembelajaran dilakukan monoton di dalam kelas.

1. Terjadi korelasi antara Pendidikan Formal terhadap Perkembangan Sosial Emosional Anak.( Spearman Correlataion)

2. Model yang mengandung intercept tidak cocok digunakan dengan kata lain model yang cocok digunakan adalah model yang mengandung variable bebas (Final Model) sesuai tabel Model Fitting Information

3. Data yang digunakan dari observasi/penelitian sesuai dengan model regresi ordinal yang digunakan dan ini berarti bahwa model yang digunakan adalah model yang paling cocok (Goodness-of-Fit)

4. Hasil dari Psudo R-Squere, hal ini mengindikasikan bahwa variabel Pendidikan Formal Orangtua mampu menjelaskan terhadap Perkembangan Sosial Emosional Anak atau dengan kata lain Pendidikan Formal Orangtua bepengaruh terhadap

12 Takdirotun Musfiroh, Bermain Untuk Pengembangan Aspek Bahasa dan Motorik, Pesona PAUD (Yogyakarta: UNY, 2011), 20. 
Perkembangan Sosial Emosional Anak.

5. Dengan tabel Parameter Estimates, dapat dijelaskan bahwa semakin tinggi nilai Pendidikan Formal kecenderungan untuk Perkembangan Sosial Emosional Anak juga naik.

6. Dari hasil uji diatas pad tabel Test of Parallel Lines, didapatkan model ordinal (proportional odds) memberi kesesuaian data yang lebih baik secara signifikan dibanding dengan general model.

\section{Simpulan}

Terdapat pengaruh yang signifikan antara pendidikan formal terhadap perkembangan sosial emosional anak di Madrasah Ibtidaiyah Thoriqussalam Sidoarjo Dua variable independent yaitu pendidikan formal orangtua berkorelasi, dengan signifikansi berbeda. Semakin tinggi pendidikan formal semakin baik akan berpengaruh lebih tinggi juga terhadap perkembangan sosial emosional anak atau sebaliknya hal ini ditunjukkan dengan analisisregresi yang terjadi.

\section{Daftar Pustaka}

Alwi, Hasan. Kamus Besar Bahasa Indonesia. Jakarta: Balai Pustaka, 2007.

Arifin, Zaenal. Metodologi Penelitian Pendidikan. Surabaya: Lentera Cendikia. 2008.

Arikunto, Suharsimi. Prosedur Penelitian Suatu Pendekatan Pendekatan Praktik. Jakarta: Rineka Cipta, 2007.

Arikunto, Suharsimi. Manajemen Penelitian. Jakarta: Rineka Cipta, 2010.

Asmawati, Luluk. Pengelolaan Kegiatan Pengembangan Anak Usia Sekolah Dasar. Jakarta: Universitas Terbuka, 2008.

Aunurrahman. Belajar dan Pembelajaran. Bandung: Alfabeta, 2009.

Bergen, Doris. "The Role of Pretend Playing Children's Cognitive Development." Early Childhood Research and Practice (Online) Vol.4, No.1 (2002).

Creswell, John W. Research Design Pendekatan Kualitatif, Kuantitatif, dan Mixed. Yogyakarta: Pustaka Pelajar, 2010.

Danes, Sharon M. Children and Money: Teaching Children Money Habits for Life. Paper published at extension youth and money resources, 2014. www.extension.umn.edu/family/personal-finance/youth-and-money/.

Dimyati. Belajar dan Pembelajaran. Jakarta: Rineka Cipta, 1999. 
Depdiknas. Pedoman Penerapan Pendekatan: Beyond Centres and Circle Time (BCCT) dalam Pendidikan Anak Usia Sekolah Dasar. Jakarta: Depdiknas, 2006.

Dhieni, Nurbiana. Metode Pengembangan Bahasa. Jakarta: Universitas Terbuka, 2007.

Essa, Eva L. Introduction to Early Childhood Education. Canada: Wadsworth Cengage, 2011.

Learning Garvey. Play: Developing Child. Massachusetts: Harvard University Press. Hurlock, Elizabeth. 2010.

Perkembangan Anak Jilid I Edisi Keenam. Jakarta: Erlangga.

Jackman, Hilda L. Early Education Curriculum. Canada: Wadsworth Cengage Learning, 2010.

Matondang, Elvrida Sandra. Meningkatkan Kemampuan Anak Usia Sekolah Dasar dalam Mengenal Konsep Bilangan Melalui Pemanfaatan Multimedia Interaktif. Bandung: Universitas Pendidikan Indonesia, 2013.

Musfiroh, Takdirotun. Bermain Untuk Pengembangan Aspek Bahasa dan Motorik, Pesona PAUD. Yogyakarta: UNY, 2011.

Mutiah, D. Psikologi Bermain Anak Usia Sekolah Dasar. Jakarta: Kencana. Nasution, 2008

Metode Research: Penelitian Ilmiah. Jakarta: Bumi Aksara, 2011.

Patmonodewo, Soemiarti. Pendidikan Anak Prasekolah. Jakarta: PT. Rineka Cipta, 2003.

Runtukahu, Tombokan. Pembelajaran Matematika Dasar Bagi Anak Berkesulitan Belajar. Yogyakarta: Ar-Ruzz Media, 2014.

Sagala, Syaiful. Konsep dan Makna Pembelajaran. Bandung: Alfabeta, 2011.

Santrock, John W. Perkembangan Anak Jilid I Edisi Kesembilan. Jakarta: Erlangga, 2007.

Slavin, Robert E. Psikologi Pendidikan Teori dan Praktek, Edisi Kedelapan Jilid 1. Jakarta: PT Indeks, 2008

Sugiyono. Metode Penelitian Kuantitatif, Kualitatif, dan R \& D. Bandung: Alfabeta, 2012.

Sujiono, Yuliani Nurani. Konsep Dasar Pendidikan Anak Usia Sekolah Dasar. Jakarta: PT. Indeks, 2013

Sumarsono, Sonny. Metode Riset Sumber Daya Manusia. Yogyakarta: Graha Ilmu, 2004.

Supriyanto, Didik. Modeling: Jurnal Program Studi PGMI 2, no. 2 (September 3, 2015).http://jurnal.stitnualhikmah.ac.id/index.php/modeling/article/view/67

Supriyanto, Didik. "Pengaruh Pendekatan Saintifik pada Pembelajaran Seni Budaya dan Prakarya terhadap Capaian Akademis Siswa Kelas IV di MI Salafiyah Syafi'iyah II Klinterejo Sooko Mojokerto." Naz̧hruna: Jurnal Pendidikan Islam 2, No. 2 (August 11, 2019). 
Surapranata, S. Analisis Validitas, Reliabilitas dan Interpretasi Hasil Tes, Implementasi Kurikulum 2004. Bandung: Remaja Rosdakarya, 2005.

Susanto, Ahmad. Perkembangan Anak Usia Sekolah Dasar. Jakarta: Kencana Prenadamedia Grup, 2012.

Suyanto, dkk. Bermain dan Permainan Anak. Jakarta: Universitas Terbuka, 2003.

Tarigan, Henry Guntur. Berbicara Sebagai Suatu Keterampilan Berbahasa. Bandung: Angkasa, 2008.

Undang-undang Sistem Pendidikan Nasional. UU RI No. 20 Tahun 2003 dan Peraturan Pelaksanaannya. Jakarta: Departemen Pendidikan Nasional, 2003

Yudhistira, Siska Y. M. Pendidikan Karakter dengan Metode Sentral. Jakarta: Media Pustaka, 2012.

Sentra. Yus, Anita. Model Pendidikan Anak Usia Sekolah Dasar. Jakarta: Kencana Prenadamedia Grup, 2014. 